\title{
Oral Cancer: Prevention and Detection
}

\author{
Bobby K. J oseph \\ Oral Diagnostic Sciences, Faculty of Dentistry, Kuwait University, Kuwait, Kuwait
}

\section{Key Words}

Cancer · Screening · Dysplasia - Tobacco · Alcohol

\begin{abstract}
Researchers in oral cancer agree that the early diagnosis of oral carcinoma greatly increases the probability of cure with minimum impairment and deformity. Primary prevention which involves reducing the exposure to tobacco, alcohol and betel quid has been shown to be effective in reducing the incidence of oral cancer. Secondary prevention involves screening for the early detection of oral cancer. Oral cancer screening can take many forms. Clinical examination and biopsy allow the early detection of premalignant and early oral cancers. Screening can be made more efficient by inspecting high-risk sites - the floor of the mouth, the ventrolateral surface of the tongue and the soft palate. Due to the cost of population screening, it is advisable to initially target high-risk groups, those over 40 years of age, including smokers and heavy drinkers. It is recommended that dentists perform an annual visual oral cancer examination on all their patients and obtain a specialist opinion for suspicious oral lesions. OraTest with toluidine blue may be used as an adjunct to soft tissue examination to highlight any invisible, asymptomatic lesions. Exfoliative cytology can detect early oral cancer and can be performed by dentally untrained personnel. It is rapid and relatively non-invasive and therefore may be useful in
\end{abstract}

population-based oral cancer screening programmes. Recently, based on various studies, the oral CDx brush biopsy technique has been proposed as a highly accurate method of detecting oral precancerous and cancerous lesions. More frequent oral cancer examinations are recommended for treated oral cancer patients to monitor the development of secondary tumours. Family members of patients with oral cancer are also at high risk and therefore should be examined more frequently. Whatever screening method is used, a positive screening result must be confirmed by biopsy. A public awareness programme that stresses the importance of at least one annual dental examination, identification of warning signs of oral cancer and recognition of the hazards of tobacco and alcohol use is necessary to reverse the high morbidity and mortality rates associated with this disease. In the future, the identification of oncogene and tumour suppressor gene mutations in biopsy specimens may give a clearer indication of the likely behaviour of suspicious oral lesions.

Copyright $\odot 2002$ S. Karger AG, Basel

\section{Introduction}

Oral squamous cell carcinoma (SCC) is the sixth commonest cancer worldwide, accounting for approximately $4 \%$ of all cancers $[1,2]$. Despite improvements in the management of diagnosed cases of oral SCC, delays in

\begin{tabular}{ll}
\hline KARGER & ( 2002 S. Karger AG, Basel \\
1011-7571/02/0115-0032\$18.50/0 \\
$\begin{array}{l}\text { Fax +41613061234 } \\
\text { E-Mail karger@karger.ch } \\
\text { www.karger.com }\end{array}$ & $\begin{array}{l}\text { Accessible online at: } \\
\text { www.karger.com/journals/mpp }\end{array}$
\end{tabular}

Dr. Bobby K. Joseph

Oral Diagnostic Sciences

Faculty of Dentistry, Kuwait University

PO Box 24923, Safat 13110 (Kuwait)

Tel. +965 2664502, ext. 7140, Fax +965 2634247, E-Mail bobby@hsc.kuniv.edu.kw 
diagnosis undoubtedly increase morbidity and mortality [3]. SCC of the oral cavity may comprise up to $50 \%$ of all cancers in developing and underdeveloped countries, and its prognosis is poor [4]. Therefore, an improvement in the prevention and control of oral cancer is of critical importance. This may be achieved by reducing the risk through avoidance of tobacco and alcohol, recognizing and treating premalignant lesions and detecting developed oral cancers at an early stage. Recent advances in the field of tumour suppressor genes and oncogenes have provided a tool for studying the genetic changes occurring at different stages of carcinogenesis, including transition from premalignancy to malignancy $[5,6]$. These strategies are directly relevant to oral cancer, which is usually preceded by well-defined premalignant stages, often leukoplakia. Detection of mutations in tumour suppressor genes or oncogenes in premalignant oral tissues might facilitate identification of individuals who are at a high risk of developing cancer [7].

\section{Causes of Oral SCC}

Oral SCC, the commonest form of oral cancer, is clearly attributable to certain lifestyles. This means that it can be regarded as preventable, even though it also occurs in patients who do not fall into the 'at risk' category [8]. Oral cancers occur in persons older than 40 , and the average age at the time of diagnosis is about 60 . Clinicians treating oral cancer are concerned that its incidence appears to be increasing at a younger age [9]. Tobacco use (both smoking and chewing) as well as alcohol consumption also contribute to the transformation of normal cells to malignant cells $[10,11]$. Prevention programmes should include measures to eliminate these habits [12].

The presence of potentially malignant oral lesions and prior history of oral cancer or other aerodigestive tract cancer are other established risk factors [13]. Additional risk factors include dietary deficiencies (mainly of vitamins $\mathrm{A}, \mathrm{C}$ and E), viral infections, Candida infection, excessive exposure to sunlight, immune suppression, familial or genetic predisposition, atmospheric pollution and chronic sepsis in the mouth [14].

There is evidence to suggest that human cancer develops as a result of genetic damage. The current hypothesis in oral carcinogenesis is that there is a relationship between tumour incidence and exposure to environmental carcinogens known to have mutagenic properties [15]. It is now recognized that normal cellular genes, when mutated or inappropriately expressed, can induce neopla- sia [16]. These genes (proto-oncogenes or cellular oncogenes) are widely expressed in normal cells, and their products (cellular oncoproteins) are thought to be fundamental in regulating the normal cellular metabolism [17]. Infection of oral keratinocytes with human papillomavirus (HPV) may be involved in the development of oral SCC in certain patients. This is supported by findings of HPV in tumour tissue and by studies showing that HPV immortalizes oral keratinocytes in vitro [18]. Chronic infection of oral keratinocytes with Candida albicans may also be involved in the development of oral SCC. It is well known that $C$. albicans stimulates epithelial cell proliferation in vitro and oral lesions of chronic hyperplastic candidiasis show epithelial dysplasia and may undergo malignant change [13]. Both public and professional awareness of oral cancer is fundamental for minimizing the time from onset of signs or symptoms to diagnosis. In most instances, patients delay seeking consultation [19]. In some cases, however, delayed diagnosis occurs because a clinician does not suspect a malignant lesion and treats it with procedures inadequate for cancer control.

\section{Clinical Presentation}

Early lesions are asymptomatic. Lesions present as a white patch, a small exophytic growth which, in the early stages, may not show ulceration or redness. Any ulcer of the mucosa which fails to heal within 2 weeks with appropriate therapy should be regarded with great suspicion [3]. Pain is not always a feature of SCCs. Clinical features which should arouse suspicion of an early carcinoma are induration, fungation, fixation to deeper structures, failure to heal of a tooth socket or any other wound, tooth mobility with no apparent cause and dysphagia with no known cause. Involvement of the lymph nodes may occur early in oral carcinoma, but enlarged lymph nodes may not indicate metastatic spread, as they may show only reactive hyperplasia [20].

White and red lesions of the oral mucosa are the most common precancerous clinical lesions. Though premalignant mucosal changes do not always precede oral cancers, such changes warn of a risk and present an opportunity for preventive measures. White changes (leukoplakia) are the most common premalignant lesions, but red changes (erythroplakia) or white changes with a red component (speckled leukoplakia, erythroplakia) carry a greater risk [21].

Med Principles Pract 2002;11(suppl 1):32-35

Oral Cancer: Prevention and Detection 


\section{Oral Cancer Prevention}

Despite advances in oral cancer therapy, the prognosis of oral SCC is still poor. Hence, emphasis should be placed on oral cancer prevention. With such well-known risk factors as tobacco and alcohol, it is possible to prevent a substantial proportion of oral cancers by reducing the exposure to these carcinogens [12]. Even in patients with precancerous oral lesions, there is encouraging evidence from a large primary intervention trial in India that the chances of these lesions undergoing malignant changes can be reduced if the patients can be persuaded to curtail their dependence on tobacco [22]. Studies from Sri Lanka [23] have shown that using primary healthcare workers to educate adults not to indulge in betel quid chewing may be 5 times more cost-effective in reducing mortality than providing high-technology treatment for cancer patients.

In addition, the risk of oral cancer may be reduced with dietary modifications, including increased intake of fresh fruits, vegetables and possibly micronutrients such as vitamins $\mathrm{C}$, A and $\mathrm{E}$. Reducing the total calories, fat, butter, eggs and starchy foods may further reduce the risk of oral cancer $[14,24]$.

\section{Oral Cancer Detection}

Oral cancer screening can take many forms [25]. Clinical and histological examination allows the early detection of premalignant and malignant lesions. Screening can be made more efficient by examining the high-risk areas where $90 \%$ of all oral SCCs arise: the floor of the mouth, the ventrolateral aspect of the tongue and the soft palate [26]. It is recommended that dentists perform an annual visual oral cancer examination on all their patients and obtain a specialist opinion for suspicious oral lesions, including idiopathic white patch (leukoplakia), speckled leukoplakia and erythroplakia [27]. More frequent oral cancer examinations are recommended for treated oral cancer patients to monitor the development of secondary tumours. Family members of patients with oral cancer are also at higher risk and, therefore, should be examined more frequently $[27,28]$.

Screening for oral cancer by visual examination is simple, inexpensive and causes little discomfort. However, there is no evidence for the effectiveness of screening for oral cancer either in reducing mortality from the disease or in reducing the incidence of invasive disease. However, routine oral examinations play an important role in controlling oral cancer [25]. Thorough examination can re- veal mucosal changes that might be premalignant or malignant. Dentists should think of prevention in two ways: (a) early detection to reduce morbidity and mortality and (b) the opportunity to identify and treat premalignant lesions.

A clinical examination by a dentist is inefficient for population-based oral screening. Exfoliative cytology can detect oral cancer and can be performed by dental hygienists [29]. This method is rapid and relatively noninvasive and therefore may be useful in population-based oral cancer screening programmes. Since exfoliative cytology can detect early oral SCC, it may be suitable within an oral SCC screening programme [29]. However, as with cervical cytology, this method can give false-negative findings as a result of inadequate sampling of lesions [29].

Due to the high cost of population screening and falsenegative findings, the current recommendation is to target 'high-risk' patients and mucosal sites. Patients exposed to high levels of carcinogens such as tobacco, alcohol or betel quid are at greater risk of oral SCC and are therefore suitable for periodic cytological screening. Other factors that may indicate increased cancer include the location of the lesion (the floor of the mouth is a high-risk site), age and sex of the patient (older males are at greater risk), a family history of cancer and individuals with cancers elsewhere. The future promise of oral exfoliative cytology is to identify early markers of oral cancer. Individuals with a genetic susceptibility to oral cancer may be identified and preventive measures taken, including the elimination of exogenous carcinogens and regular monitoring [29].

The other diagnostic aid which is used is topical $1 \%$ toluidine blue, which binds selectively to dysplastic and malignant oral epithelial cells [30]. Accordingly, toluidine blue can be used as a diagnostic aid for patients at risk from oral cancer as well as for delineating biopsy sites [31]. However, as toluidine blue is a suspected carcinogen, its repeated use for assessing 'high-risk' patients and premalignant lesions is associated with some risk [32, 33].

Recently, to improve the detection of precancerous and cancerous oral lesions, the Oral $\mathrm{CDx}$, a computerassisted method of analysis of the oral brush biopsy, has been introduced [34]. This is a highly accurate method to determine the significance of an oral lesion definitively and detect innocuous-appearing oral cancers at early, curable stages [34].

Whatever screening method is used, a positive screening result must be confirmed by biopsy. 


\section{Conclusions}

As discussed, the survival rate for patients with oral SCC is showing no sign of improvement. Hence, until more effective treatment modalities are available, emphasis should be placed on primary prevention (reducing exposure to carcinogens in the form of tobacco and alcohol) and secondary prevention (early detection and treatment). Clinicians should remain alert to signs and symptoms of oral cancer and premalignancy in persons who regularly use tobacco or alcohol.

\section{References}

1 Moore SR, Johnson NW, Pierce AM, Wilson DF: The epidemiology of mouth cancer: A review of global incidence. Oral Dis 2000;6: 65-74.

2 Moore SR, Johnson NW, Pierce AM, Wilson DF: The epidemiology of tongue cancer: A review of global incidence. Oral Dis 2000;6: 75-84.

3 Vokes EF, Weichselbaum RR, Lipman SM, Hong WK: Head and neck cancer. N Engl J Med 1993;328:184-194

4 Daftary DK: The situation in high risk areas of the world; in Johnson NW (ed): Risk Markers for Oral Diseases. Cambridge, Cambridge University Press, 1990, vol 2.

5 Field JK: Oncogenes and tumour-suppressor genes in squamous cell carcinoma of the head and neck. Eur J Cancer B Oral Oncol 1992; 28B:67-76.

6 Sugerman PB, Savage NW: Current concepts in oral cancer. Aust Dent J 1999;44:147-156.

7 Sugerman PB, Joseph BK, Savage NW: The role of oncogenes, tumour suppressor genes and growth factors in oral squamous cell carcinoma: A case of apoptosis versus proliferation. Oral Dis 1995;1:172-188.

8 Warnakulasuriya KAAS, Johnson NW: Epidemiology and risk factors for oral cancer: Rising trends in Europe and possible effects of migration. Int Dent J 1996;46:245-250.

9 Llewellyn CD, Johnson JW, Warnakulasuriya KAAS: Risk factors for squamous cell carcinoma of the oral cavity in young people - A comprehensive literature review. Oral Oncol 2001; 37:401-418

10 Johnson J: Tobacco use and oral cancer: A global perspective. J Dent Educ 2001;65:328339 .

11 Blot WJ: Alcohol and cancer. Cancer Res 1992; 52:2119-2223.

12 La Vecchia C, Tavani A, Franceschi S, Levi F, Corroa G, Negri E: Epidemiology and prevention of oral cancer. Oral Oncol 1997;63: $517-525$
13 Scully C, Cawson R: Potentially malignant oral lesions. J Epidemiol Biostat 1996;1:3-12.

14 Zain RB: Cultural and dietary risk factors for oral cancer and precancer: A brief overview. Oral Oncol 2001;37:205-210.

15 Todd R, Donoff RB, Wong DT: The molecular biology of oral carcinogenesis: Toward a tumour progression model. J Oral Maxillofac Surg 1997;55:613-623.

16 Friedrich RE, Giese M, Riethdorf S, Loning T: $\mathrm{p}^{53}$ mutation in smears of oral squamous cell carcinoma. Anticancer Res 2000;20:49274930.

17 Todd R, Wong DT: Oncogenes. Anticancer Res 1990;19:4729-4746.

18 Sugerman PB, Shillitoe EJ: The high risk human papillomaviruses and oral cancer: Evidence for and against a causal relationship. Oral Dis 1997;3:130-147.

19 Kumar S, Heller RF, Panday U, Tewari V, Bala $\mathrm{N}$, Oanh KT: Delay in presentation of oral cancer: A multifactor analytical study. Natl Med J India 2001;14:13-17.

20 Jordan RC, Daley T: Oral squamous cell carcinoma: New insights. J Can Dent Assoc 1997; 63:517-525

21 Sudbo J, Kildal W, Risberg B, et al: DNA content as a prognostic marker in patients with oral leukoplakia. N Engl J Med 2001;344: 1270-1278.

22 Gupta PC, Mehta FS, Pindborg JJ, et al: Primary intervention trial of oral cancer in India: A 10-year follow-up study. J Oral Pathol Med 1992;21:433-439.

23 Warnakulasuriya KAAS: Utilization of primary health care workers for the early detection of oral cancer and precancer cases in Sri Lanka. Bull WHO 1984;62:243-250.
24 Winn D: Diet and nutrition in the etiology of oral cancer. Am J Clin Nutr 1995;61(suppl): 437S-450S.

25 Speight PM, Downer MC, Zakrzewska J: Screening for oral cancer and precancer: A report of a UK working group on screening for oral cancer and precancer. Community Dent Health 1993;10(suppl):1-89.

26 Downer MC, Evans AW, Hughes H, Hallet CM, Jullien JA, Speight PM, Zakrzewska JM Evaluation of screening for oral cancer and precancer in a company headquarters. Community Dent Oral Epidemiol 1995;23:84-88.

27 McCann MF, Macpherson LM, Gibson J: The role of general dental practitioners in detection and prevention of oral cancer: A review of literature. Dent Update 2000;27:404-408.

28 Johnson NW, Warnakulasuriya KAAS, Partridge M, Langdon JD: Oral cancer: A serious and growing problem. Ann R Coll Surg Engl 1995; 77:321-322.

29 Sugerman PB, Savage NW: Exfoliative cytology in clinical oral pathology. Aust Dent J 1996; 41:71-74.

30 Warnakulasuriya KAAS, Johnson NW: Sensitivity and specificity of OraScan ${ }^{\circledR}$ toluidine blue mouth rinse in the detection of oral cancer and precancer. J Oral Pathol Med 1996;25:97_ 103.

31 Feldman RS, Mooney JW, Epstein J, Bainbridge TC, Allaire N: Trial of toluidine blue as an oral cancer diagnostic aid. J Dent Res 1998; 77:1024.

32 Danford N: The genetic toxicology of orthotoluidine. Mutat Res 1991;258:207-236.

33 Sellers C, Markowitz S: Re-evaluating the carcinogenicity of ortho-toluidine: A new conclusion and its implications. Regul Toxicol Pharmacol 1992;16:301-317.

34 Sciubba JJ: Detecting oral cancer: Computerassisted analysis of oral brush biopsy. J Am Dent Assoc 1999;130:1445-1457. 